\title{
Erratum: Androgyny and Sex-Typing: Differences in Beliefs Regarding Gender Polarity in Ratings of Ideal Men and Women (Vol. 9, No.4)
}

\author{
Karla S. McPherson ${ }^{1}$ and Susan K. Spetrino ${ }^{2}$
}

The College of Wooster

Regarding the Spence and Helmreich entry in Table IV on page 449, it was erroneously printed that the $n$ for males and females separately was 715 each. 715 should have appeared as the combined $n$ for males and females. A corrected Table IV is reproduced on the following page.

\footnotetext{
${ }^{1}$ Correspondence should be sent to the first author, Department of Psychology, The College of Wooster, Wooster, Ohio 44691.

${ }^{2}$ Now at the University of North Carolina School of Law.
} 


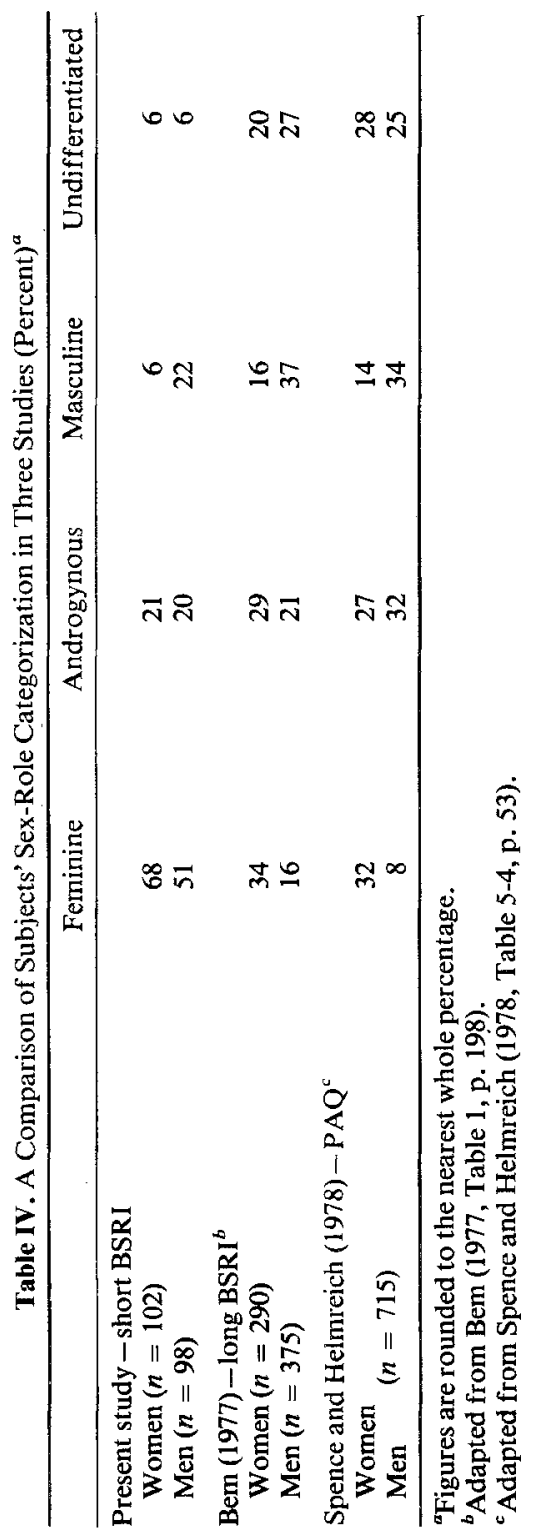

